University of Nebraska - Lincoln

DigitalCommons@University of Nebraska - Lincoln

Ecosystem processes, land cover, climate, and human settlement shape dynamic distributions for golden eagle across the western US

J.D. Tack

B.R. Noon

Z.H. Bowen

B.C. Fedy

Follow this and additional works at: https://digitalcommons.unl.edu/usgsstaffpub

Part of the Geology Commons, Oceanography and Atmospheric Sciences and Meteorology Commons, Other Earth Sciences Commons, and the Other Environmental Sciences Commons

This Article is brought to you for free and open access by the US Geological Survey at DigitalCommons@University of Nebraska - Lincoln. It has been accepted for inclusion in USGS Staff -- Published Research by an authorized administrator of DigitalCommons@University of Nebraska - Lincoln. 


\title{
Ecosystem processes, land cover, climate, and human settlement shape dynamic distributions for golden eagle across the western US
}

\author{
J. D. Tack ${ }^{1,2}$ (D) B. R. Noon ${ }^{1}$, Z. H. Bowen ${ }^{2}$ \& B. C. Fedy ${ }^{3}$ \\ 1 Department of Fish, Wildlife, and Conservation Biology, Colorado State University, Fort Collins, CO, USA \\ 2 US Geological Survey, Fort Collins Science Center, Fort Collins, CO, USA \\ 3 Environment, Resources and Sustainability, University of Waterloo, Waterloo, ON, Canada
}

\begin{abstract}
Keywords
Aerial survey; Aquila chrysaetos; golden eagle; hierarchical Bayesian inference; human footprint; occupancy dynamics; ecosystem processes.
\end{abstract}

\section{Correspondence \\ Jason D. Tack. Current address: US Fish and Wildlife Service, Habitat and Population \\ Evaluation Team, Missoula, MT, USA. \\ Email: jason_tack@fws.gov \\ Editor: Res Altwegg \\ Associate Editor: Michael Schaub}

Received 07 June 2017; accepted 01 April 2019

doi:10.1111/acv.12511

\begin{abstract}
Species-environment relationships for highly mobile species outside of the breeding season are often highly dynamic in response to the collective effects of everchanging climatic conditions, food resources, and anthropogenic disturbance. Capturing dynamic space-use patterns in a model-based framework is critical as model inference often drives place-based conservation planning. We applied dynamic occupancy models to broad-scale golden eagle Aquila chrysaetos survey data collected annually from 2006 to 2012 during the late summer post-fledging period in the western US. We defined survey sites as $10 \mathrm{~km}$ transect segments with a $1 \mathrm{~km}$ buffer on either transect side $(n=3540)$. Derived estimates of occupancy were low (4.4-7.9\%) and turnover rates - the probability that occupied sites were newly occupied - were high (88-94\%), demonstrating that annual transiency in occupancy dominates late summer behavior for golden eagles. Despite low philopatry during late summer, variation in golden eagle occupancy could be explained by a suite of land cover and annual-varying covariates including gross primary productivity, drought severity, and human disturbance. Our summary of 13 years of predicted occupancy by golden eagles across the western United States identified areas that are consistently used and that may contribute significantly to golden eagle conservation. Restricting development and targeting mitigation efforts in these areas offers practitioners a framework for conservation prioritization.
\end{abstract}

\section{Introduction}

Understanding the key dimensions that define a species' relationship to its environment has been a foundational component of ecology since its inception, formalized decades ago in the theory of the niche. From a conservation perspective, it is imperative to identify and understand the relationships between a species and its environment in light of increasing rates of global change in both land use and climate (Steffen, Crutzen \& McNeill, 2007). Current and projected rates of species declines driven by anthropogenic impacts are unprecedented and influenced by multiple drivers including energy development (Allred et al., 2015) and agricultural expansion (Tilman et al., 2001). Both of these drivers of change lead to a direct loss of habitat, and these losses are often exacerbated by synergisms with human-caused climate change and expanding distributions of exotic species (Mantyka-Pringle, Martin \& Rhodes, 2012). Thus, a comprehensive conservation strategy must address two key challenges: identifying the critical dimensions of the fundamental niche of the species and identifying those landscapes capable of meeting the species' current and future resource needs. In response to these challenges, the conservation community has adopted a biogeographic approach that focuses on the spatial distribution of species at multiple scales (Whittaker et al., 2005). Contributing significantly to this biogeographic perspective on nature conservation has been the rapid development of analytical methods to estimate species' fundamental niches, generically termed species distribution models (SDMs; Guisan et al., 2013). Today, studies of the niche, in the form of SDMs, are a prominent topic of ecological research, stimulated in large part by concern over how species will respond to rapid environmental change.

Generally, SDMs are any model-based tool for understanding multidimensional ecological relationships by relating a suite of environmental covariates to species locations using either statistical models or machine-learning algorithms. Common applications of SDMs within a conservation context include their incorporation into multi-species reserve-designs (e.g. Cabeza \& Moilanen, 2001), projecting changes to 
species distributions under climate change (e.g. Araùjo et al., 2005), projecting range expansions by invasive species (e.g. Ficetola, Thuiller \& Miaud, 2007), and evaluating candidate areas for species reintroductions or translocations (e.g. Osborne \& Seddon, 2012). In practice, most SDMs are correlative, and based on historic or contemporary survey data (often presence-only) that may provide only a snapshot of the species' environmental relationships over some temporally constrained window. Such constrained SDMs only represent the predicted distribution at the time of sampling, implicitly assume the relationships between a species and its environment are at equilibrium (Araùjo et al., 2005), and make assumptions about consistent species-environment relations through time (niche conservatism; e.g. Stephens \& Wiens, 2009). Yet in light of rapid ongoing global change, the species-environment relationships that ultimately shape species' geographic distributions may be increasingly dominated by transient dynamics (Yackulic et al., 2015).

Golden eagles Aquila chrysaetos are a widely distributed species that occupy vast, rugged landscapes across the northern hemisphere, with annual ranges that can be continental in scale (Kochert et al., 2002). In the western United States (US), golden eagle populations currently appear to be stable (Millsap et al., 2013; Nielson et al., 2014), though there is a growing concern that increased anthropogenic energy development and land-use change may result in significant population declines. The US, for example, is one of many nations expected to experience increased growth in renewable energy development, of which wind energy will play a prominent role (US Energy Information Administration 2013). Wind turbines are a known, potentially significant source of mortality for golden eagles (Hunt, 2002; Pagel et al., 2013). This additive source of mortality is of concern for species with slow life histories, such as most birds of prey, because even small reductions in adult survival can result in significant declines in population growth (Riley, Degloria \& Elliot, 1999; Whitfield et al., 2004; Chevallier et al., 2015; Tack et al., 2017). Current projections suggest that energy production from wind turbines may increase by an order of magnitude over the next 35 years in the US (US Energy Information Administration 2013), emphasizing the need to enact proactive conservation measures in areas where energy development overlaps the geographic range of golden eagles (Tack \& Fedy, 2015).

In areas projected to experience extensive wind power development in the future, SDMs can be useful tools for prioritizing conservation efforts for golden eagles during the early phases of planning for the location of wind turbines (Tack \& Fedy, 2015). Using predictions from SDMs during the planning phase is also of benefit to the energy industry because it provides a way to address the regulatory requirements of the Bald and Golden Eagle Protection Act and to avoid litigation by placing wind energy projects in areas with minimal potential harm to eagle populations (https:// www.fws.gov/migratorybirds/pdf/management/eagleconser vationplanguidance.pdf).

However, traditional SDMs may fail to encompass the dynamic nature of golden eagle space use, particularly during non-breeding seasons when individuals are not confined to nest sites and greatly expand their range (Watson, Duff \& Davies, 2014). Recently developed models that estimate parameters to account for the dynamic nature of species distribution patterns clearly demonstrated the role of temporal variation in interpreting species-environment relationships (Guisan \& Zimmermann, 2000; Guisan \& Thuiller, 2005). Occupancy models represent an improvement to many presence-only SDMs by accounting for imperfect detectability at survey locations. Dynamic occupancy models expand this framework to estimate transitions in occupancy among sites via local colonization and persistence processes over time, while simultaneously accounting for heterogeneity in the observation process (MacKenzie et al., 2018). As a result, occupancy models represent an improvement to many presence-only SDMs by accounting for imperfect detectability at survey locations.

We fit dynamic occupancy models to golden eagle detection/non-detection data collected annually from a western US survey. The survey's primary goal is to estimate total population size and trend across most suitable habitats within the western US (Good et al., 2007). Our objectives were fourfold: (1) to parameterize a model that accounts for the dynamic use of habitat over time, while accounting for imperfect detection; (2) to elucidate how temporal and spatial variation in climate, ecosystem processes, and human settlement patterns collectively result in dynamic geographic distributions of golden eagles; (3) to develop predictive models to inform conservation planning for golden eagles; and (4) to identify landscape-level mitigation actions that, to the extent possible, buffer the adverse effects of future land-use change.

\section{Materials and methods}

\section{Study area and golden eagle surveys}

Golden eagles were surveyed from 2006 to 2012 using fixed-wing aircraft across four US Bird Conservation Regions (BCRs), spanning the majority of the western US golden eagle distribution (Kochert et al., 2002; Fig. 1). The BCRs included in our analyses encompassed shrublands and desert of the Great Basin, prairies and badlands of the western Great Plains, and mixed vegetative communities including forested landscapes in the intermountain West along the Rocky Mountains. Sources of fragmentation within BCRs included tillage agriculture, human-developed areas, and infrastructure for energy development. Golden eagle surveys were conducted each year over a 3-week period during late summer (18 August to 9 September). During this time, juvenile eagles have fledged and dispersed from nesting territories, and are no longer dependent on parental care.

Two survey teams, each composed of three observers (a few flights had only two observers in 2008) and one pilot, flew $100 \mathrm{~km}$ transects at $150 \mathrm{~m}$ above ground level (AGL) in relatively flat habitat, while flying lower at $100 \mathrm{~m}$ AGL in more rugged landscapes. Front and rear observers on the right side of the aircraft searched for perched or flying eagles 


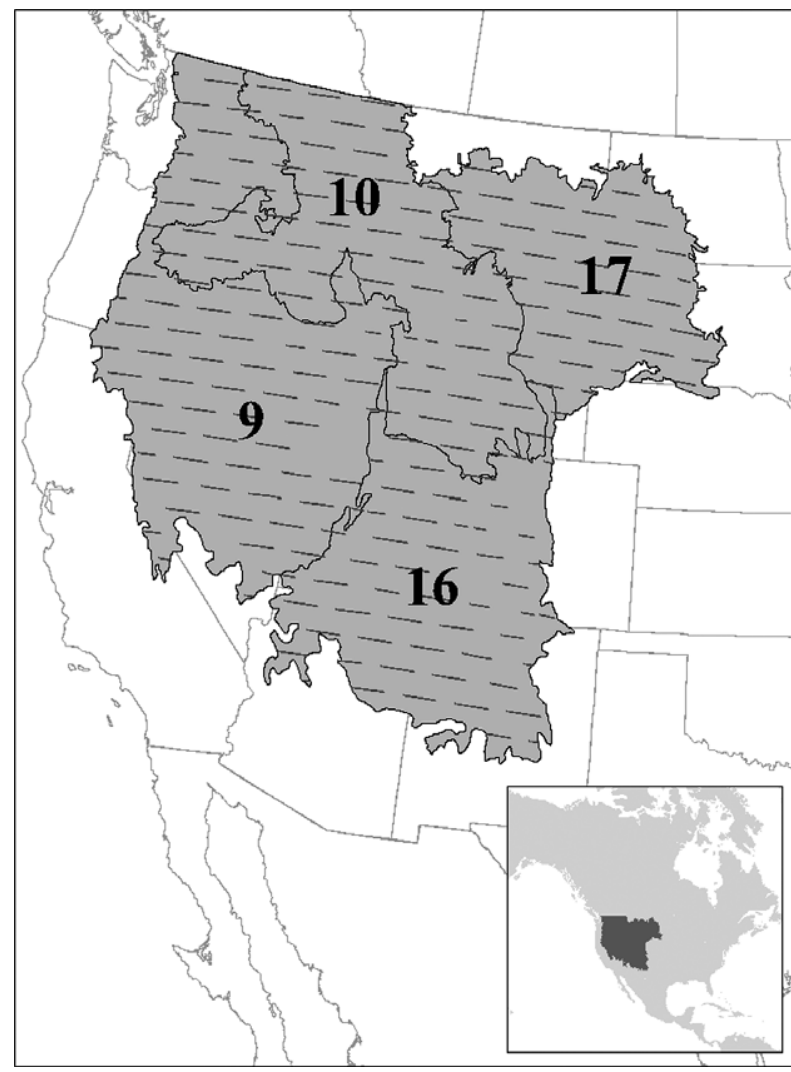

Figure 1 The study area encompassed US portions of 4 North American Bird Conservation Regions: 9 Great Basin, 10 Northern Rockies, 16 Southern Rockies/Colorado Plateau, 17 Badlands and Prairies. Lines represent primary (not alternate) transects from which golden eagles were surveyed by aircraft from 2006-2012.

independently of one another, while the third, rear-seated side observer searched for eagles to the left side of the plane. Because right-side observers did not communicate detections until they passed an eagle, their counts were deemed independent replicate surveys of sites, with observer independence further ensured by a partition between the front and rear seats. Observers recorded the location, age class (subadult or adult), count, and behavior (perched, flying) for all eagle detections. Not all transects could be surveyed each year due to wildfire or other access issues. In these cases, alternate transects were chosen and surveyed. We only used data from transects surveyed at least twice over the duration of the study to assess changes in occupancy over time. For more detail on the survey methodology and design, see Good et al. (2007).

Our goal was to model spatial variation in eagle distributions at a scale that reflected golden eagle behavior during the late summer. Therefore, we partitioned each transect into $10 \mathrm{~km}$ length segments, and created sample 'sites' by buffering either side of the transect by $1 \mathrm{~km}$. For example, a $100 \mathrm{~km}$ site contained 20 distinct, $10 \mathrm{~km}^{2}$ sites (10 on either side of a transect), which was within the range of a golden eagle territory size during the outside of the breeding season
(Marzluff et al., 1997). Not all transects were exactly $100 \mathrm{~km}$, such as when transects abutted the edge of the sampling frame, and we retained these 'trailing' sites that were $<10 \mathrm{~km}$ as long as they were $\geq 5 \mathrm{~km}$ in length. Eagle detections were subsequently assigned to sites based on GPS locations and observer position. In total, we classified 3540 sites across 220 transects, from which observers made detections of 811 golden eagles across sites. The majority of observations included detections of only one golden eagle $(80.9 \%)$ leading us to use occupancy rather than count-based models, though as many as four eagles were observed on some sites $(0.5 \%)$. For a full description of the dataset, see Nielson et al. (2012). While our sampling period encompassed approximately three weeks in late summer, it is important to note that estimated state variables are conflated with the availability of golden eagles for detection because sites were only sampled on 1 day. Therefore, estimates of initial occupancy and persistence are likely biased low.

\section{Predictor variables}

Golden eagle distributions are affected by multiple environmental factors and anthropogenic disturbances that vary in space and time (Nielson et al., 2016). Fluctuating resource levels and an increasing human footprint are particularly relevant to wide-ranging predators which travel long distances in an attempt to track seasonally variable prey resources. We identified four classes of covariates hypothesized to influence eagle occupancy during the post-breeding late summer season: (1) climatic factors and primary productivity hypothesized to drive variation in prey distribution and abundance; (2) topographic features conducive to flight, foraging and movement by raptors (Katzner et al., 2012); (3) the anthropogenic footprint reflecting human use and land cover conversion from cropland agriculture, urbanization, and energy development; and (4) dominant vegetation (i.e. land cover).

During late summer (Jul-Sep), golden eagles primarily prey on lagomorphs (Lepus spp; Sylvagius spp) and other small to medium-sized mammals (Kochert et al., 2002). Spatial data on prey distribution or abundance were not available across the spatial and temporal extent of our study, though we assumed variation in primary productivity and drought severity would be useful proxies reflecting changes in prey availability at large spatial scales (Huntly \& Inouye, 1988). We used MODIS gross primary productivity (GPP) data available at $1 \mathrm{~km}$ resolution over 8 day intervals, and assigned the most recent GPP estimate to each site. Similarly, we hypothesized that drought conditions at local scales would depress herbivore populations (Myers \& Parker, 1975), so we used data from the Standardized PrecipitationEvapotranspiration Index (SPEI; http://sac.csic.es/spei/databa se.html), a multi-scalar drought index summarized over 3 (summer drought; June 1 - September 1) and 12-month (annual; September 1 - September 1) time intervals, where negative values are indicative drier time periods. We calculated a terrain ruggedness index (TRI; Riley et al., 1999) as the standard deviation of $30 \mathrm{~m}$ elevation data within a neighborhood from the National Elevation Dataset (Gesch et al., 
2002), and calculated the mean of TRI values within each site. We calculated the extent of the human footprint by combining multiple sources of temporally dynamic data on energy development, cultivated agriculture, human development, and road networks into a single comprehensive data layer (Kiesecker et al., 2011). To characterize croplands, we extracted areas identified as cultivated agriculture using National Land Cover Datasets (NLCD) from 2006 and 2011. We also identified areas characterized as low to high-intensity developed areas from NLCD data to capture human settlement. Road surfaces, and other human development features were characterized using NLCD impervious surface layers. We obtained spatially referenced data on well location, status, and drilling (spud) date from state oil and gas commissions. If a producing well was drilled prior to a given eagle survey, we converted these point data to a binary raster (well or no well) for each year. We applied a similar procedure to wind turbine location data (Diffendorfer et al., 2014). We used a USGS Topographic Change Polygon which delineates mines and other areas of human impact that result in non-natural changes in elevation (http://topocha nge.cr.usgs.gov). Each disturbance spatial data set was reclassified as either disturbed or undisturbed areas using the resolution of the largest the minimum mapping unit $(30 \mathrm{~m})$. NLCD data were the only spatial data not available for each year of the study. In these cases, we used data from previous years to calculate annual covariates (i.e. 2006 data were used for 2006-2010 layers, and 2011 data were used onward). We also considered latitude and longitude to account for unmeasured sources of spatial variation inherent in this large-scale dataset (Karanth et al., 2014), and included their quadratic terms to account for non-monotonic relationships that may arise from higher occurrence toward the center of golden eagle range (Brown, Mehlman \& Stevens, 1995). Lastly, we used NLCD land cover data to calculate the proportion of woodland, shrubland, and grassland and herbaceous cover types within each site.

\section{Model fitting}

We fit a Bayesian state-space parameterization of a dynamic occupancy model (Royle \& Kery, 2007) to the golden eagle survey data. Using this approach, eagle detections $\left(y_{i, j, t}\right)$ in a given year $(t)$ at a site $(i)$ by one of two independent observers $(j)$, are expressed as the joint probability of the site truly being occupied $\left(z_{i, t}\right)$, and the probability that an eagle is detected by an observer $\left(p_{i, j, t}\right)$ over the course of $J_{i, j, t}$ surveys.

$$
y_{i, j, t}\left\{\begin{array}{lr}
0 ; & \text { when } z_{i, t}=0 \\
\operatorname{Bernoulli}\left(p_{i, j, t}\right) ; & \text { when } z_{i, t}=1
\end{array}\right.
$$

Occupancy was estimated from a Bernoulli distribution conditioned on the initial year of the survey in 2006.

$$
z_{i, 2006} \sim \operatorname{Bernoulli}\left(\psi_{i, 2006}\right)>
$$

In subsequent years (2007-2012), we modeled the dynamic processes associated with occupancy including persistence $\left(\phi_{i, t}\right)$ - the probability that a site occupied in year $t$ is also occupied in year $t+1$, and colonization $\left(\gamma_{i, t}\right)-$ the probability that an unoccupied site in year $t$ is occupied in year $t+1$, to characterize dynamic changes in distributional patterns. Transition probabilities of persistence and colonization were modeled as autoregressive, conditional on occupancy in the previous year.

$$
z_{i, t} \begin{cases}\operatorname{Bernoulli}\left(\phi_{i, t-1}\right) ; & \text { when } z_{i, t-1}=1 \\ \operatorname{Bernoulli}\left(\gamma_{i, t-1}\right) ; & \text { when } z_{i, t-1}=0\end{cases}
$$

Occupancy following the first year of observation was then derived from a previous state, along with site-specific transition probabilities.

$$
\psi_{i, t}=\psi_{i, t-1} \phi_{i, t-1}+\left(1-\psi_{i, t-1}\right) \gamma_{i, t-1}
$$

Similarly, we were also interested in turnover rates $\left(\tau_{i, t}\right.$; Nichols et al., 1998), or the probability that a used site was newly occupied in a given year, to characterize heterogeneity in annual occupancy among sites.

$$
\tau_{i, t}=\frac{\gamma_{i, t-1}\left(1-\psi_{i, t-1}\right)}{\gamma_{i, t-1}\left(1-\psi_{i, t-1}+\phi_{i, t-1} \psi_{i, t-1}\right)}
$$

We were primarily interested how multiple factors influenced heterogeneity in site occupancy by golden eagles, and built logit-linear models with covariates to explain variation in the processes of detection, initial occupancy, and site dynamics (persistence and colonization). We considered coefficients for initial occupancy, persistence, and colonization parameters including covariates for drought, GPP, land cover, and a human footprint. We also considered these variables to explain variation in detection, and because some segments at the terminal end of a transect were $<10 \mathrm{~km}$, we also considered a covariate for transect length. Lastly, we considered a surveyor-specific covariate which identified technicians as front or rear observers in case position within the plane influenced detection.

All covariates were scaled $(\bar{x} / s d(x))$ to facilitate convergence and comparison among coefficient estimates. Because there was limited information on golden eagle space use at the spatial and temporal scale of our study, we assumed weakly informative normal prior distributions $(\mu=0$, $\tau=0.37$ ) for each estimated parameter. We estimated posterior distributions from three MCMC chains using 30000 iterations each following 20000 sampled as burn-in. We visually inspected chains and calculated Gelman-Rubin convergence diagnostics across parameters to confirm parameter estimates had converged (Gelman \& Rubin, 1992).

The original sample units (transects) were partitioned into smaller subsets leading to a potential lack of independence among sites within each transect. To address this possibility, we fit covariate models for initial occupancy, colonization, and persistence including flight transect as a random effect to account for potential spatial dependency within transects (Miller \& Grant, 2015). For example, when estimating initial occupancy, we estimated intercept terms as $\alpha_{[\text {transect }]} \sim \operatorname{Normal}\left(\mu_{\psi, 2006}, \sigma_{\psi, 2006}^{2}\right)$, where $\mu_{\psi, 2006} \sim$ Normal $(\mu=0, \tau=0.37)$ and $\sigma_{\psi, 2006}^{2} \sim \operatorname{Gamma}(0.001,0.001)$. 


\section{Model selection}

Prior to fitting model for inference, we used AIC model selection to determine the best fit covariate model structure for detection and occupancy parameters, by fitting dynamic occupancy models using a likelihood framework with $\mathrm{R}$ package unmarked (Fiske \& Chandler, 2011). This likelihood-based approach allowed us to use a powerful and computationally efficient method for exploratory model selection (Burnham \& Anderson, 2002; Broms et al., 2016), but also prohibited us from fitting random effects for transects, which required the aforementioned Bayesian approach to account for spatial dependence. We first excluded highly collinear covariates $(r>|0.6|)$ from appearing in the same model by retaining only the variables with the lowest AIC scores from model fitting univariate models. Second, we fit all possible combinations of covariates (the reduced set) to model detection probability, while using fully parameterized (e.g. all covariates) models for occupancy and dynamics parameters. We chose the most parameterized model with a $\triangle \mathrm{AIC}$ value of $<2$ for use in subsequent models (Burnham \& Anderson, 2002). We repeated this approach to determine the model structure for initial occupancy, colonization and persistence, again using full-parameterized models among the two occupancy parameters not being fit with all possible combinations of models. Lastly, once the final covariate structure was identified for each model, we fit additional models with time-varying intercepts using AIC to determine if we should include fixed year effects in our Bayesian model. Bayesian models were fit using program R and JAGs with package rjags (Plummer, 2013).

\section{Spatial predictions}

We applied spatial model predictions for each year across the extent of the study area using a $10 \mathrm{~km}^{2}$ grid for mapping occupancy (estimated in 2006, derived 2007-2012), persistence, and colonization. These projections were based on median values from posterior distributions of coefficient estimates from the final model. We also derived maps for the coefficient of variation, calculated as the median estimate of occupancy divided by one-half of the width of $95 \%$ credible intervals, to provide spatial representations of uncertainty. Additional data on time-variant covariates (GPP \& SPEI) were available for years 2002-2014, which allowed us to develop spatial predictions across and we predicted colonization and persistence probability spatially in these years, deriving a forecast of occupancy probability following predictions in 2012 (2013-2014), and hindcasting occupancy using initial occupancy estimates applied to years 20022005. This provided 13 years of temporally variable spatial predictions of golden eagle occupancy across the western US. We summarized these data to provide an overall picture of mean occupancy for each site $\left(\bar{\psi}_{i}\right)$, and the coefficient of variation among occupancy probabilities $\left(\psi_{c v, i}=\frac{\bar{\psi}_{i}}{s d\left(\psi_{i}\right)}\right)$ as an index of site stability over time.

\section{Results}

Model selection results implicated site length, proportion woodland, and terrain ruggedness as covariates in the top model for detection probability (Table S1). Anthropogenic disturbance and GPP (main and quadratic terms) explained significant amounts of the temporal and spatial variation in multiple parameters including initial occupancy, persistence, and colonization (Table S1). Land cover variables for woodland, shrubland, and grassland were all included in the initial occupancy model, while the colonization model included shrubland and grassland and the persistence model included only the woodland covariate (Table S1). Terrain ruggedness index was included in initial occupancy models and the SPEI drought index was included among dynamic parameters for colonization and persistence. Lastly, fixed year effects improved model fit for occupancy parameters after identifying all top coefficient models.

The population-level estimate of initial occupancy, with covariates held at their mean values, was $\psi_{2006}=0.04$ (Table 1), while mean estimates for persistence and colonization ranged from 0.06 to 0.17 and 0.04 to 0.07 , respectively, resulting in ranges of derived occupancy from 0.05 to 0.08 (Table 1). Sites with low estimates of occupancy were characterized by high turnover rates from 0.88 to 0.94 (Table 1). Mean detection probability, with covariates held at their mean values were 0.80 (95\% CRI 0.77, 0.83). Detection estimates were negatively influenced by the proportion of woodland $(-0.12 ; 95 \% \mathrm{CRI}-0.41,0.18)$, and terrain ruggedness $(-0.08 ; 95 \%$ CRI $-0.35,0.17)$ of sites, whereas results were equivocal for the influence of site length $(0.04 ; 95 \%$ CRI $-0.14,0.20)$.

Table 1. Transformed estimates of initial golden eagle occupancy, persistence, and colonization over the course of the study with covariates held at their mean values. Occupancy following the first year (2006) and turnover rate - the probability that an occupied site was newly occupied - were derived from estimates (see methods)

\begin{tabular}{lllll}
\hline Year & Occupancy & Persistence & Colonization & Turnover Rate \\
\hline 2006 & $0.04(0.03,0.07)$ & $0.17(0.06,0.36)$ & $0.07(0.02,0.20)$ & $0.91(0.67,0.98)$ \\
2007 & $0.08(0.03,0.20)$ & $0.17(0.08,0.30)$ & $0.05(0.04,0.07)$ & $0.92(0.71,0.98)$ \\
2008 & $0.07(0.04,0.15)$ & $0.10(0.05,0.20)$ & $0.04(0.03,0.06)$ & $0.92(0.81,0.97)$ \\
2009 & $0.05(0.04,0.11)$ & $0.10(0.05,0.21)$ & $0.05(0.03,0.06)$ & $0.88(0.75,0.95)$ \\
2010 & $0.06(0.04,0.11)$ & $0.13(0.06,0.24)$ & $0.05(0.04,0.07)$ & $0.94(0.86,0.98)$ \\
2011 & $0.06(0.04,0.13)$ & $0.06(0.02,0.14)$ & $0.04(0.03,0.05)$ & $0.88(0.76,0.95)$ \\
2012 & $0.05(0.03,0.08)$ & & & \\
\hline
\end{tabular}


Mean coefficient estimates were generally consistent across occupancy parameters and significant, with credible intervals strictly positive or negative, while many did overlap 0 such that their influence should be interpreted as equivocal. Mean coefficient estimates for GPP, both main and quadratic terms, were consistently negative across all occupancy parameters (Fig. 2). Coefficients estimating the influence of drought were positive for both dynamic parameters, indicating lowered persistence and colonization with increasing drought conditions (Fig. 2). All land cover coefficient estimates were positive across models, with the exception of the influence of shrublands on colonization. Increasing human disturbance had a negative influence on both initial occupancy and persistence, while a positive influence was estimated for colonization (Fig. 2). Visual inspection confirmed that posterior distributions had converged, and Gelman-Rubin statistics supported adequate mixing across chains $(r<1.01)$.

Applying posterior mean coefficient estimates to spatial covariate data produced spatially explicit predictions for initial occupancy, colonization, and persistence, from which occupancy in 2007-2012 could be derived (Fig. 3). Covariate data gathered during 2002-2005 and 2013-2014 provided an additional six years of spatial predictions. Summarizing across the combined 12 years of predictions produced an overall mean occupancy estimate and the coefficient of variation across years (Fig. 4).

\section{Discussion}

Habitat use is a behavioral trait that may evolve through time, particularly for wide-ranging predators (Nielsen et al., 2010; Northrup, Anderson \& Wittemyer, 2015). Transient occupancy was prominent in our system with at least $88 \%$ of sites estimated as newly occupied across years. High turnover, however, does not equate to golden eagle spatial occupancy patterns being unpredictable. Static habitat features including terrain ruggedness and location within the range (reflecting unmeasured sources of environmental variation) were consistent predictors of occupancy. However, dynamic covariates such as climate change and land cover associated with an expanding human footprint had the greatest explanatory power across spatially referenced predictors of golden eagle space use.

In contrast to low site fidelity during late summer, golden eagles show highly philopatric behavior during the breeding season (approximately March-July; Kochert et al., 2002).

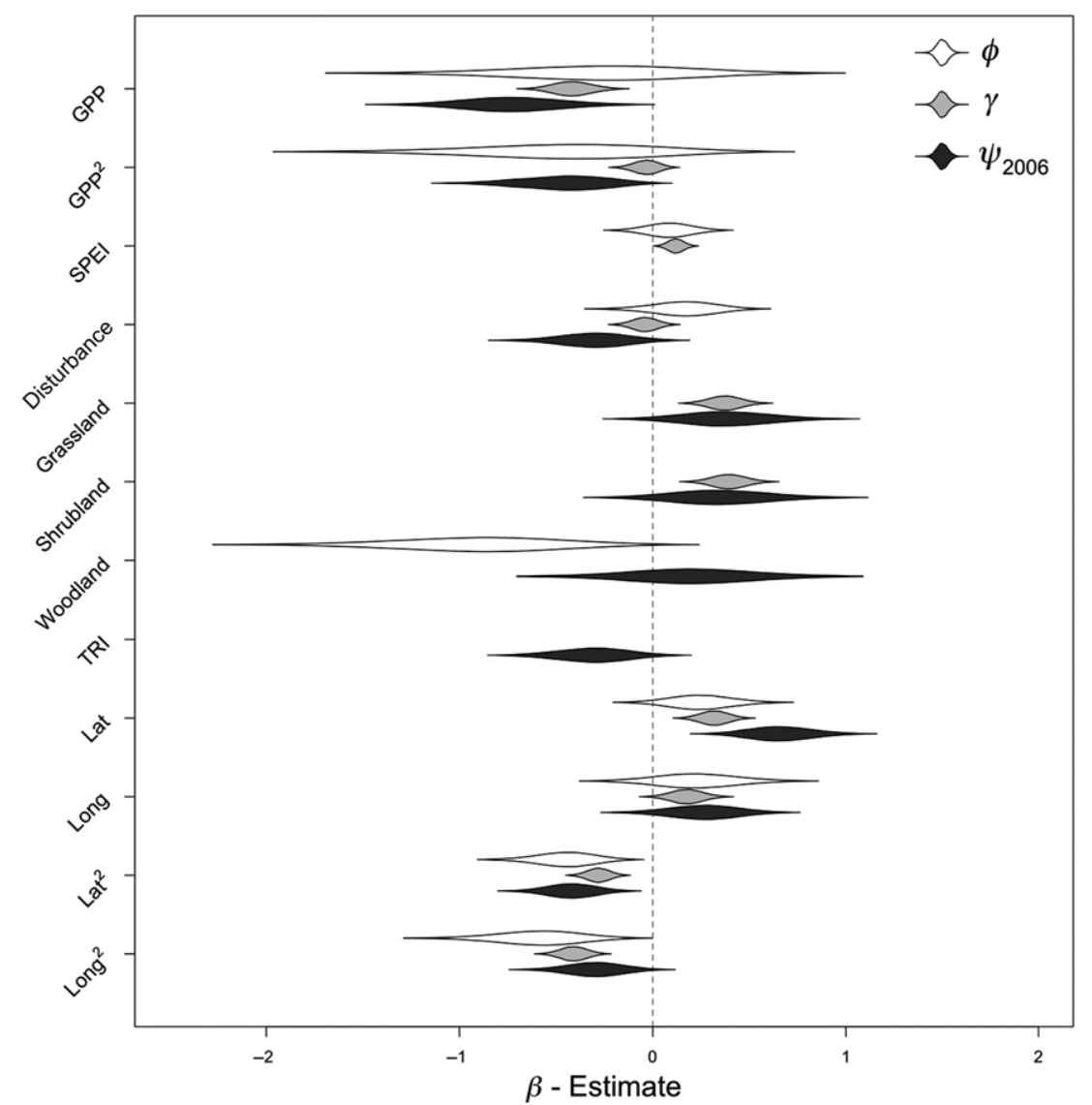

Figure 2 Coefficient estimates for covariates gross primary productivity (GPP) and its quadratic term (GPP2), terrain ruggedness (TRI), combined anthropogenic disturbance (Disturbance), drought severity over a 3-month window (SPEI); land cover metrics describing the proportion of grassland, woodland and shrubland; and latitude (Lat) and '1longitude (Lon) with quadratic terms. Coefficients were estimated for initial occupancy probability $\left(\psi_{2006}\right)$, and dynamic parameters for colonization $(\gamma)$ and persistence $(\phi)$, of golden eagles. 

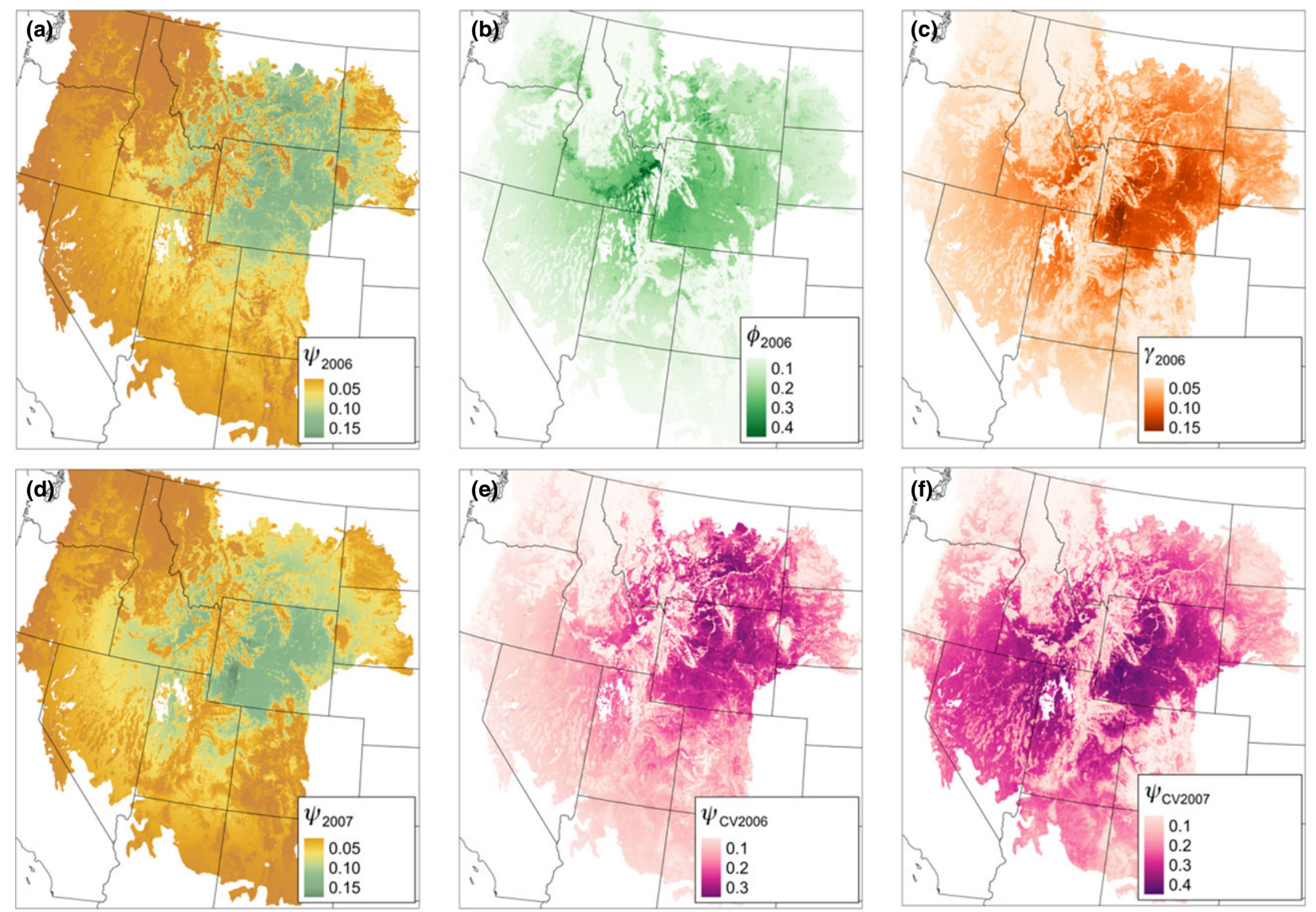

Figure 3 Using a $1 \mathrm{~km}^{2}$ grid across the study area, we generated spatial predictions of initial occupancy (a; $\left.\psi_{2006}\right)$, and parameters describing site dynamics including persistence $\left(\mathrm{b} ; \phi_{2006}\right)$ and colonization $\left(\mathrm{c} ; \gamma_{2006}\right)$. Using these outputs, future predictions of occupancy could then be derived $\left(\mathrm{d} ; \psi_{2007}\right)$, displaying the dynamic nature of golden eagle occupancy during late summer. Examples of spatial variation associated with parameters for occupancy are displayed for $2006\left(e ; \psi_{c v, 2006}\right)$ and $2007\left(f ; \psi_{c v, 2007}\right)$. [Colour figure can be viewed at zslpublications. onlinelibrary.wiley.com]

These findings confirm the importance of documenting space-use patterns following the breeding season and document the dynamic nature of late summer habitat-use patterns. While it is generally appreciated that particular landscapes vary seasonally in their use by wildlife populations, little attention has focused on the degree of heterogeneity of interannual patterns of space use. Failing to account for annual variation in patterns of eagle space use in survey designs could result in an incomplete understanding of their habitat requirements and temporal variability in population distribution. Intensive local-scale surveys are the primary tool for identifying golden eagle habitat use, and assessing potential adverse impacts, prior to constructing energy infrastructure. However, our results suggest that short-term studies of eagle space use may fail to capture dynamic changes in space use and underestimate the spatial extent of habitat needed for long-term conservation. Thus, it is imperative that impact analyses be based on survey results accumulated over multiple years (e.g. USFWS 2013).

Prey distribution and abundance were likely the key determinants of golden eagle habitat-use patterns during late summer - however, data on prey abundance were not available at the spatial scale of our study. Instead, we had to rely on spatial surrogates known to influence prey distributions (Fernàndez, Romàn \& Delibes, 2016). Gross primary productivity had the largest effect on occupancy parameters among all the predictors we evaluated. It is important to note that GPP measurements are higher in forested systems compared to sagebrush and grassland systems, such that lower GPP values may reflect highly productive rangelands within the study system. While our model estimated a positive influence of forested landscapes on initial occupancy and persistence, estimates were lower than those for shrubland and herbaceous metrics. Importantly, within and among vegetation community types, extensive annual variation in plant productivity was evident. For example, GPP measurements across the Wyoming Basin - an arid non-forested landscape characterized by Wyoming big sagebrush (Artemisia tridentata wyomingensis.) communities - varied by an average of $45 \%$ over the seven years of the study (Tack unpublished data). Annual variation in plant productivity, combined with a generally positive effect of SPEI (e.g. non-drought conditions) on colonization, suggests that golden eagles may be selecting productive areas while avoiding drought-stricken landscapes. 

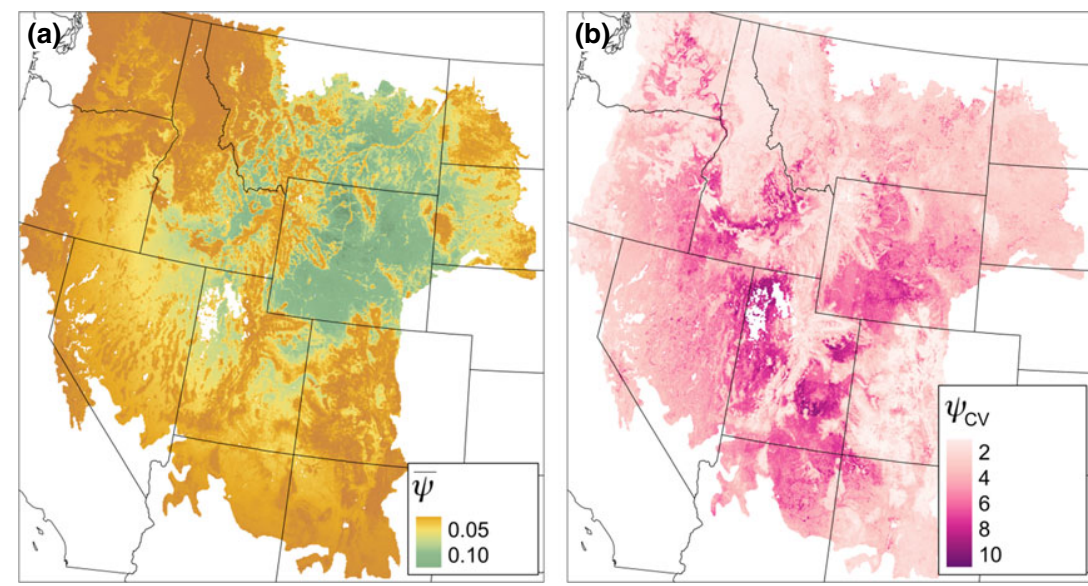

Figure 4 Available covariate data allowed us to make spatial predictions for the years 2002-2014, from which we derived mean occupancy for each site as $\bar{\psi}_{i}=\frac{1}{13} \sum_{t=2002}^{2014} \psi_{i, t}$, to display the central tendency of occupancy probability across the study area (a), which highlights the Snake River Plains, the Wyoming Basin, and the Northwest Great Plains as critical areas for golden eagle use during late summer. We also derived the coefficient of variation for occupancy across years $\psi_{c v, i}=\frac{\bar{\psi}_{i}}{s d\left(\psi_{i, t}\right)}$, to represent spatial variation in occupancy relative to the mean (b). The Wyoming Basin underscores a region with consistently high predicted use, while the Colorado Plateaus region of Utah is highlighted as a region with very low variation in intermediate golden eagle use. [Colour figure can be viewed at zslpublications.onlinelibrary.wiley.com]

Golden eagles largely avoided areas with an extensive human footprint, demonstrated by negative mean coefficients for initial occupancy and colonization, while mean positive coefficients were estimated for all natural land cover variables. However, the impact of human infrastructure on the persistence of occupancy was slightly positive. It is possible that landscapes highly altered by humans could support high eagle use if prey densities were also high. For example, Altamont Wind Power Resource Area is dominated by wind energy infrastructure, yet supports some of the highest densities of golden eagles globally, likely due to the high density of California ground squirrels in the area (Otospermophilus beecheyi; Hunt \& Hunt, 2006). Furthermore, not all human disturbances result in avoidance. For example, certain infrastructure (e.g. power poles) may actually attract use by eagles (Lehman, Kennedy \& Savidge, 2007). A key unknown is whether such areas could act as population sinks if eagle mortality were high as a consequence of energy infrastructure. Adverse effects of human disturbance on initial occupancy and colonization parameters suggest that emerging and novel disturbances are likely to degrade golden eagle habitat through avoidance behavior.

Human infrastructure in the western US is projected to experience continued growth, in large part a consequence of expanding wind energy development. As a result, it is important to develop a conservation framework that identifies species-environment relationships in light of anticipated energy development. From a demographic perspective, management of golden eagle populations should focus on minimizing losses in breeding adult survival because this is the key demographic rate among slow life-history species (Gerber \& Kendall, 2016; Millsap et al., 2016; Tack et al., 2017). However, minimizing the effects of any additive eagle mortality arising from energy development will require a landscape-scale conservation strategy that accounts for regional variation in patterns of space use, a likely consequence of shifting availability of golden eagle prey across the landscape. Areas with consistently high occupancy, defined as those with high occupancy mean and low coefficient of variation, may be landscapes where development should be limited and prioritized for mitigation efforts.

The spatial locations we identified as critical to long-term conservation broadly correspond with a recent spatial analysis of the same dataset using a count-based model summarized across eight years of surveys (Nielson et al., 2016). Even though our response variables differed (intensity of use vs initial occupancy and dynamic parameters), both of our results documented the importance of sagebrush habitats in Wyoming and the northern portion of the Great Basin, and temperate grasslands within the Northwest Great Plains as regionally important areas for golden eagles during late summer.

Our finding of golden eagle avoidance for initial occupancy of human-dominated landscapes and low colonization of new sites in highly disturbed areas, suggests an energy development strategy which directs future development to areas already highly transformed by human use (Kiesecker et al., 2011). We predict that additional development in areas already heavily transformed by human use will have significantly lower impact on golden eagles than development in undisturbed areas. In addition, because of the dynamic nature of the distribution of landscapes with sufficient prey resources, the spatial extent of areas needed for golden eagle conservation may need to be both extensive and relatively free of human transformation.

\section{Acknowledgements}

We acknowledge and thank Robert Murphy, Brian Millsap, Ryan Nielson and the WEST Inc. flight crews for designing, 
and safely collecting data used in this analysis. Luke George provided comments on a previous draft of this manuscript. Larissa Bailey, Mevin Hooten, and Tom Hobbs provided analytical guidance at various stages during this project. Any use of trade, firm, or product names is for descriptive purposes only and does not imply endorsement by the U.S. Government.

\section{References}

Allred, B.W., Smith, W.K., Twidwell, D., Haggerty, J.H., Running, S.W., Naugle, D.E. \& Fuhlendorf, S.D. (2015). Ecosystem services lost to oil and gas in North America. Science 348, 401-402.

Araùjo, M.B., Pearson, R.G., Thuiller, W. \& Erhard, M. (2005). Validation of species-climate impact models under climate change. Glob. Change Biol. 11, 1504-1513.

Broms, K.M., Hooten, M.B., Johnson, D.S., Altwegg, R. \& Conquest, L.L. (2016). Dynamic occupancy models for explicit colonization processes. Ecology 97, 194-204.

Brown, J.H., Mehlman, D.W. \& Stevens, G.C. (1995). Spatial variation in abundance. Ecology 76, 2028-2043.

Burnham, K.P. \& Anderson, D.R. (2002). Model selection and multimodel inference: a practical information-theoretic approach. Verlag, New York: Springer.

Cabeza, M. \& Moilanen, A. (2001). Design of reserve networks and the persistence of biodiversity. Trends Ecol. Evol. 16, 242-248.

Chevallier, C., Hernández-Matías, A., Real, J., Vincent-Martin, N., Ravayrol, A. \& Besnard, A. (2015). Retrofitting of power lines effectively reduces mortality by electrocution in large birds: an example with the endangered Bonelli's eagle. J. Appl. Ecol. 52, 1465-1473.

Diffendorfer, J.E., Compton, R., Kramer, L., Ancona, Z. \& Norton, D. (2014). Onshore industrial wind turbine locations for the United States through July, 2013. US Geological Survey.

Fernàndez, N., Romàn, J. \& Delibes, M. (2016). Variability in primary productivity determines metapopulation dynamics. Proc. R. Soc. Biol. Sci. Ser. B. 283, 20152998.

Ficetola, G.F., Thuiller, W. \& Miaud, C. (2007). Prediction and validation of the potential global distribution of a problematic alien invasive species - the American bullfrog. Divers. Distrib. 13, 476-485.

Fiske, I. \& Chandler, R. (2011). unmarked: an R package for fitting hierarchical models of wildlife occurrence and abundance. J. Stat. Soft. 43, 1-23.

Gelman, A. \& Rubin, D.B. (1992). Inference from iterative simulation using multiple sequences. Stat. Sci. 7, 457-472.

Gerber, B.D. \& Kendall, W.L. (2016). Considering transient population dynamics in the conservation of slow life-history species: an application to the sandhill crane. Biol. Conserv. 200, 228-239.

Gesch, D., Oimoen, M., Greenlee, S., Nelson, C., Steuck, M. \& Tyler, D. (2002). The national elevation dataset. Photogr. Eng. Remote Sens. 68, 5-11.
Good, R.E., Nielson, R.M., Sawyer, H. \& McDonald, L.L. (2007). A population estimate for golden eagles in the western United States. J. Wildl. Manag. 71, 395-402.

Guisan, A. \& Thuiller, W. (2005). Predicting species distribution: offering more than simple habitat models. Ecol. Lett. 8, 993-1009.

Guisan, A. \& Zimmermann, N.E. (2000). Predictive habitat distribution models in ecology. Ecol. Model. 135, 147-186.

Guisan, A., Tingley, R., Baumgartner, J.B., Nauokaitis-Lewis, I., Sutclie, P.R., Tulloch, A.I.T., Regan, T.J., Broton, L., McDonald-Madden, E., Mantyka-Pringle, C., Martin, T.G., Rhodes, J.R., Maggini, R., Setterfield, S.A., Elith, J., Schwartz, M.W., Wintle, B.A., Broennimann, O., Austin, M., Ferrier, S., Kearney, M.R., Possingham, H.P. \& Buckley, Y.M. (2013). Predicting species distributions for conservation decisions. Ecol. Lett. 16, 1424-1435.

Hunt, W.G. (2002). Golden Eagles in a Perilous Landscape: Predicting the Effects of Mitigation for Wind Turbine Bladestrike Mortality. California Energy Commission (CEC) Consultant Report P500-02-043F, CEC Sacramento, California. July 2002. Prepared for CEC. Public Interest Energy Research (PIER), Sacramento, California, by University of California, Santa Cruz, California. Available at: http://www. energy. ca. gov/reports/2002-11-04_500-02043F.

Hunt, G. and Hunt, T. (2006). The trend of golden eagle territory occupancy in the vicinity of the Altamont Pass Wind Resource Area: 2005 survey. Unpublished report of the California energy Commission, PIeR energy-Related environmental Research, CeC-500-2006-056.

Huntly, N. \& Inouye, R. (1988). Pocket gophers in ecosystems: patterns and mechanisms. Bioscience 38, 786793.

Karanth, K.K., Nichols, J.D., Sauer, J.R., Hines, J.E. \& Yackulic, C.B. (2014). Latitudinal gradients in North American avian species richness, turnover rates and extinctions probabilities. Ecography 37, 626-636.

Katzner, T., Smith, B.W., Miller, T.A., Brandes, D., Cooper, J., Lanzone, M., Brauning, D., Farmer, C., Harding, S., Kramar, D.E., Koppie, C., Maisonneuve, C., Martell, M., Mojica, E.K., Todd, C., Tremblay, J.A., Wheeler, M., Brinker, D.F., Chubbs, T.E., Gubler, R., O'Malley, K., Mehus, S., Porter, B., Brooks, R.P., Watts, B.D. \& Bildstein, K.L. (2012). Status, biology, and conservation priorities for North America's eastern Golden Eagle (Aquila chrysaetos) population. Auk 129, 168-176.

Kiesecker, J.M., Evans, J.S., Fargione, J.Ho, Doherty, K., Foresman, K.R., Kunz, T.H., Naugle, D.E., Nibbelink, N.P. $\&$ Niemuth, N.D. (2011). Win-win for wind and wildlife: a vision to facilitate sustainable development. PLOS ONE 6, e17566.

Kochert, M.N., Steenhof K., McIntyre, C.L \& Craig, E.H. 2002. Golden eagle (Aquila chrysaetos). Account 684 in Poole, A. \& Gill, F. editors. The birds of North America. The Academy of Natural Sciences, Philadelphia, 
Pennsylvania, and the American Ornithologists' Union, Washington, D.C., U.S.A.

Lehman, R.N., Kennedy, P.L. \& Savidge, J.A. (2007). The state of the art in raptor electrocution research: a global review. Biol. Conserv. 136, 159-174.

MacKenzie, D.I., Nichols, J.D., Royle, J.A., Pollock, K.H., Bailey, L.L. \& Hines, J.E. (2018). Occupancy estimation and modeling. 2nd edn. Sand Diego, CA: Academic Press.

Mantyka-Pringle, C.S., Martin, T.G. \& Rhodes, J.R. (2012). Interactions between climate and habitat loss effects on biodiversity: a systematic review and meta-analysis. Glob. Change Biol. 18, 1239-1252.

Marzluff, J.M., Knick, S.T., Vekasy, M.S., Schueck, L.S. \& Zarriello, T.J. (1997). Spatial use and habitat selection of golden eagles in southwestern Idaho. Auk 114, 673-687.

Miller, D.A.W. \& Grant, E.H.C. (2015). Estimating occupancy dynamics for large-scale monitoring networks: amphibian breeding occupancy across protected areas in the northeast United States. Ecol. Evol. 5, 4735-4746.

Millsap, B.A., Zimmerman, G.S., Sauer, J.R., Nielson, R.M., Otto, M., Bjerre, E. \& Murphy, R. (2013). Golden eagle population trends in the western United States: 1968-2010. J. Wildl. Manag. 77, 1436-1448.

Millsap, B.A., Bjerre, E.R., Otto, M.C., Zimmerman, G.S. \& Zimpfer, N.L. (2016). Bald and golden eagles: population demographics and estimation of sustainable take in the United States, 2016 update. Washington, DC: Division of Migratory Bird Management.

Myers, K. \& Parker, B.S. (1975). Effect of severe drought on rabbit numbers and distribution on a refuge area in semiarid north-western New South Wales. Aust. Wildl. Res. 2, 103-120.

Nichols, J.D., Boulinier, T., Hines, J.E., Pollock, K.H. \& Sauer, J.R. (1998). Estimating rates of local species extinction, colonization and turnover in animal communities. Ecol. Appl. 8, 1213-1225.

Nielsen, S.E., McDermid, G., Stenhouse, G.B. \& Boyce, M.S. (2010). Dynamic wildlife habitat models: seasonal foods and mortality risk predict occupancy-abundance and habitat selection in grizzly bears. Biol. Conserv. 143, 1623-1634.

Nielson, R.M., McManus, L., Rintz, T. \& McDonald, L.L. (2012). A survey of golden eagles (Aquila chrysaetos) in the western US, 2006-2012. Cheyenne, WY: Western EcoSystems Technology Inc.

Nielson, R.M., McManus, L., Rintz, T., Mcdonald, L.L., Murphy, R.K., Howe, W.H. \& Good, R.E. (2014). Monitoring abundance of golden eagles in the western United States. J. Wildl. Manag. 78, 721-730.

Nielson, R.M., Murphy, R.K., Millsap, B.A., Howe, W.H. \& Gardner, G. (2016). Modeling late-summer distribution of golden eagles (Aquila chrysaetos) in the western United States. PLOS ONE 11, e0159271.

Northrup, J.M., Anderson, C.R. \& Wittemyer, G. (2015). Quantifying spatial habitat loss from hydrocarbon development through assessing habitat selection patterns of mule deer. Glob. Change Biol. 21, 3961-3970.
Osborne, P.E. and Seddon, P.J. (2012). Selecting suitable habitats for reintroductions: variation, change and the role of species distribution modelling. In Reintroduction Biology: Integrating Science and Management, 1st edn: 73-104. Ewen, J.G., Armstrong, D.P., Parker, K.A. and Seddon, P.J. (Eds). Oxford: Wiley-Blackwell.

Pagel, J.E., Kritz, K.J., Millsap, B.A., Murphy, R.K., Kershner, E.L. \& Covington, S. (2013). Bald eagle and golden eagle mortalities at wind energy facilities in the contiguous United States. J. Raptor Res. 47, 311-315.

Plummer, R. (2013). Rjags: Bayesian graphical models using MCMC. R package version 4.8. Available at: https://cran.rproject.org/web/packages/rjags/rjags.pdf (Accessed 28 Dec 2018).

Riley, S.J., Degloria, S.D. \& Elliot, R. (1999). A terrain ruggedness index that quantiies topographic heterogeneity. Intermt. J. Sci. 5, 23-27.

Royle, J.A. \& Kery, M. (2007). A Bayesian state-space formulation of dynamic occupancy models. Ecology 88, 1813-1823.

Steffen, W., Crutzen, P.J. \& McNeill, J.R. (2007). The Anthropocene: are humans now overwhelming the great forces of nature. Ambio. J. Hum. Environ. 36, 614-621.

Stephens, P.R. \& Wiens, J.J. (2009). Bridging the gap between community ecology and historical biogeography: niche conservatism and community structure in emydid turtles. Mol. Ecol. 18, 4664-4679.

Tack, J.D. \& Fedy, B.C. (2015). Landscapes for energy and wildlife: conservation prioritization for golden eagles across large spatial scales. PLOS ONE 10, e0134781.

Tack, J.D., Noon, B.R., Bowen, Z.H., Strybos, L. \& Fedy, B.C. (2017). No substitute for survival: perturbation analyses using a golden eagle population model reveals limits to managing for take. J. Raptor Res. 51, 258272.

Tilman, D., Fargione, J., Wolff, B., D'Antonia, C., Dobson, A., Howarth, R., Schindler, D., Schlesinger, W.H., Simberloff, D. \& Swackhamer, D. (2001). Forecasting agriculturally driven global environmental change. Science 292, 281-284.

US Energy Information Administration (2013). Annual energy outlook 2013. Washington, DC: US Energy Information Administration.

US Fish and Wildlife Service. (2013). Eagle conservation plan guidance. Module 1 - land-based wind energy. Version 2. Washington, DC: Division of Migratory Bird Management, US Department of Interior.

Watson, J.W., Duff, A.A. \& Davies, R.W. (2014). Home range and resource selection by GPS-monitored adult golden eagles in the Columbia Plateau Ecoregion: implications for wind power development. J. Wildl. Manag. 78, 1012-1021.

Whitfield, D.P., Fielding, A.H., McLeod, D.R.A. \& Haworth, P.F. (2004). The effects of persecution on age of breeding and territory occupation in golden eagles in Scotland. Biol. Conserv. 118, 249-259. 
Whittaker, R.J., Araújo, M.B., Jepson, P., Ladle, R.J., Watson, J.E. \& Willis, K.J. (2005). Conservation biogeography: assessment and prospect. Divers. Distrib. 11, 3-23.

Yackulic, C.B., Nichols, J.D., Reid, J. \& Der, R. (2015). To predict the niche, model colonization and extinction. Ecology 96, 16-23.

\section{Supporting information}

Additional supporting information may be found online in the Supporting Information section at the end of the article.
Table S1. Model selection results among all possible combinations of candidate variables for models on detection, initial occupancy, persistence, and colonization within a dynamic occupancy model. 